\title{
Road Traffic Injuries and their Outcome in the Elderly Patients 60 years and above. Does Age make a Difference?
}

Malik AM ${ }^{1 *}$, Dal NA ${ }^{2}$ and Talpur $\mathrm{KAH}^{2}$

${ }^{1}$ Department of surgery, College of Medicine, Qassim University, Kingdom of Saudi Arabia

${ }^{2}$ Department of Surgery, Liaquat University of Medical and Health Sciences, Jamshoro, Sind, Pakistan

\begin{abstract}
Objective: To investigate the injury pattern, management and outcome of road traffic injuries in the elderly patients (60 years and above) involved in motor vehicle accidents and to compare factors associated with trauma and differences in trauma mortality between elderly and younger adult patients.

Methods: This is a retrospective descriptive study conducted at a teaching hospital during Jun 2002 to Jan 2010, studying the differing pattern, and management of road traffic injuries in patients aged 60 years and above, designated as Group-A, and those below 60 years of age, designated as Group -B, regardless of gender of the patients.

All the patients were referred through casualty and were assessed clinically followed by relevant investigations. Patients who sustained minor injuries were discharged after necessary treatment while those with serious injuries requiring intervention were admitted and managed accordingly. Patients having purely orthopaedic problems like isolated fractures or spine injuries were also excluded from the study. Treatment was instituted according to the severity of the trauma ranging from conservative treatment to laparotomy and chest intubation. The variables studied included demographics of both groups of patients, pattern of injuries sustained in both groups, trauma indices ISS and GCS, mechanism of injury, major injuries sustained, treatment instituted, mean number of hospital days, and morbidity and mortality.
\end{abstract}

Details of individual patients were recorded on a proforma and data analyzed statistically on SPSS version 17.

Results: A total 300 patients (Group-A $n=149[49.66 \%]$ versus Group-B $n=151[50.33 \%]$ ) admitted and intervened were included in the study. Male patients predominated both the groups (Group-A. [Mean age 66.91, Std 6.859, Males $n=115$, Females $n=34$ ] vs Group-B [Mean age 35.52, Std 13.814, Males $n=140$, Females $n=11]$ ). The group-A patients had significantly higher proportion of co-morbidities $(p<0.001)$ compared to group-B patients $(64.42 \%$ versus $18.66 \%)$. The mortality rises progressively with age and is almost twice as high as in younger population at all levels of severity of trauma. Incidence of chest injuries with rib fractures was more common in elderly victims $(P<0.001)$ compared to the younger patients $(40.26 \%)$ versus $(12.58 \%)$. The overall in hospital mortality in Group-A patients was $14.76 \%$ compared to (4.63) in group-B for an almost comparable severity of injuries sustained.

Conclusion: The incidence of road traffic accidents is on the rise in the elderly. The elderly patients have a different pattern of road traffic injuries and they respond poorly to the sustained injuries despite low ISS compared to the younger patients.

Keywords: Elderly patients; Road traffic injuries; Co-morbidities; Mortality; Morbidity; Younger patients.

\section{Introduction}

Advancing age is known to increase adverse outcome after road traffic accidents. Despite an overall lower incidence of traumatic injuries in elderly, the mortality is comparatively high in the geriatric patients [1]. Since there is an increased incidence of associated co-morbidities of varying severity as well as decreased physiological reserve, the elderly are claimed to have poorer outcomes in traumatic injuries and need an aggressive management $[2,3]$. Elderly patients are reported to sustain different types of injuries compared to their younger counterparts due to trauma as well as a mortality of $50 \%$ above that of general population [4-6]. It is yet to be confirmed whether this difference in outcome is due to decreased physiologic reserve, co-morbidities or some other factors. An aggressive management is recommended by most of the authors to improve outcome in road traffic traumatic injuries in the elderly patients [7].

\section{Patients and methods}

This retrospective descriptive study compared an almost equal number of elderly patients (60 years and above designated as Group-A) and younger patients $(<60$ years ,designated as Group-B) admitted with history of road traffic accident demanding hospitalization during a span of 7 years in a teaching hospital. All patients were referred through casualty department with varying degrees and proportion of injuries. The patients were initially resuscitated and examined thoroughly for injuries and using the Abbreviated Injury Score (AIS) categorized into minor, moderate, serious and severe injuries. The organ injury scales were also referred for those who had abdominal injury demanding laparotomy as well as those who had chest trauma. After resuscitative measures and establishment of the diagnosis, the

*Corresponding author: Arshad M. Malik, Associate Professor, Department of Surgery, College of Medicine, Qassim University, Kingdom of Saudi Arabia, Tel: 009665553692608; E-mail: arshadhamzapk@yahoo.com

Received March 22, 2012; Accepted April 13, 2012; Published April 16, 2012

Citation: Malik AM, Dal NA, Talpur KAH (2012) Road Traffic Injuries and their Outcome in the Elderly Patients (60 years and above). Does Age make a Difference? J Trauma Treat 1:129. doi:10.4172/2167-1222.1000129

Copyright: (C) 2012 Malik AM, et al. This is an open-access article distributed under the terms of the Creative Commons Attribution License, which permits unrestricted use, distribution, and reproduction in any medium, provided the original author and source are credited. 
patients were managed accordingly. The variables studied in both groups were demographics, mechanism of injury, injuries sustained, co-morbidities, treatment instituted, total hospital stay, and outcome of the treatment. The co-morbidities meant any chronic disease/ diseases for which patient is taking medicine on regular basis such as diabetes mellitus, hypertension etc. as well as any cancer or history of a major operation in the near past.

The details of each patient were recorded on a proforma and data was statistically analyzed using SPSS version 17.

\section{Results}

Group- A included 149 patients (Mean age 66.91, Std 6.859, Males $\mathrm{n}=115$, Females $\mathrm{n}=34$ ), admitted with history of road traffic accident with varying injuries. This group of elderly trauma victims is compared to a similar number of patients in group-B (Mean age 35.52, Std 13.814, Males $n=140$, Females $n=11$ ) and managed during the same duration. Majority of the patients in both groups were brought to hospital within 12 hours of the incidence while overall $15 \%$ patients including both groups reported after more than 24 hours. There was a rise in the incidence of road traffic trauma in the elderly patient during the study period, as evident from Table 1 .

\section{Co-morbidity}

A significantly higher proportion of group-A ( $n=96,[64.42 \%])$ had one or the other co- morbidities such as diabetes mellitus, hypertension, and IHD, compared to their younger counter-parts as shown in Table 2 .

\section{Mechanism of injury}

In both the groups, the majority of the patients received injuries by a variety of vehicles ranging from motorcycles to cars and bus/trucks etc. Majority (74.49\%) of group-A victims were passengers (Vehicle occupants) where as $63 \%$ of group-B patients were drivers. The major trauma distribution and injuries sustained in both groups was different as shown in Table 3.

\section{Pattern of injuries}

There is a significantly high incidence of chest wall injuries with rib fractures and haemo-pneumothorax in the elderly patients $(\mathrm{P}<0.001)$ compared to their younger counterparts. Similarly, the incidence of limb and hip bone fracture is significantly higher $(\mathrm{P}<0.001)$ in the elderly patients as compared to the younger age group. The chest injuries in elderly are associated with an increased incidence of complications like basal atelectasis and pneumonia Patients with rib fractures and associated haemo-pneumothorax needed chest intubation, antibiotics and adequate analgesia while six of them needed multiple blood transfusions and had severe respiratory distress with a flail segment. These patients died within 4 hours of admission in the ward before they could be shifted to ICU. The remaining patients were discharged after successful recovery. The abdominal injuries requiring laparotomy were much more common in the younger age group patients ( 89 vs. 33) and the pattern of injuries was also different in two groups as shown in Table 4. The total number of patients treated in ICU included 79(53\%) patients of group-A compared to 23(15\%) of the group-B $(<0.05)$. The ISS for group-A was significantly less than group-B as shown in Table 5 .

\begin{tabular}{|c|c|c|c|}
\hline Year & $\begin{array}{c}\text { Total Number of Trauma Patients } \\
\text { requiring admission }\end{array}$ & $\mathbf{> 6 0}$ years of age & \multicolumn{2}{c|}{$\begin{array}{c}\text { Number of patients requiring } \\
\text { hospitalization and intervention }\end{array}$} \\
\hline 2002 & 276 & $32(11.59 \%)$ & $244(88.40 \%)$ \\
\hline 2003 & 298 & $45(15.10 \%)$ & $253(84.89 \%)$ \\
\hline 2004 & 344 & $36(10,46 \%)$ & $308(89.53 \%)$ \\
\hline 2005 & 421 & $49(11.63 \%)$ & $39(13.08 \%)$ \\
\hline 2006 & 402 & $137(34.07 \%)$ & $230(8.72 \%)$ \\
\hline 2007 & 399 & $182(45.61 \%)$ & $265(65.92 \%)$ \\
\hline 2008 & 517 & $201(38.87 \%)$ & $217(54.38 \%)$ \\
\hline 2009 & 377 & $156(41.37 \%)$ & $316(61.12 \%)$ \\
\hline 2010 & 483 & $237(49.06 \%)$ & $221(58.62 \%)$ \\
\hline Total & 3517 & $1075(30.56 \%)$ & $246(50.93 \%)$ \\
\hline
\end{tabular}

Table 1: Yearly incidence of Road traffic accident showing increasing incidence of elderly victims.

\section{Co-Morbidities}

\begin{tabular}{|c|c|c|c|c|c|c|c|}
\hline & Hypertension and IHD. & Diabetes Mellitis & COPD & Renal disease & Neurological disorder & Defective vision & Total \\
\hline$>60$ years & 29 & 31 & 15 & 03 & 07 & 11 & $96(64.42 \%)$ \\
\hline$<60$ years & 07 & 09 & 11 & 01 & 00 & 00 & $28(18.66 \%)$ \\
\hline
\end{tabular}

$\mathrm{P}<0.001$

Table 2: Prevalence of Co-morbidities in two groups.

\begin{tabular}{|l|l|l|l|l|l}
\hline Age Group & Fractured ribs with haemo-pneumothorax & Blunt abdominal injury requiring laparotomy & Fracture of limb bones or hip bone & Multiple injuries
\end{tabular} 60 and above $60(\mathrm{P}<0.001)$

\begin{tabular}{l|l|l|l}
$<60$ years & 19
\end{tabular}

$33 \quad 31(\mathrm{P}<0.001)$
111

Table 3: Comparison of injuries sustained in two groups.

Abdominal Injuries

\begin{tabular}{|c|c|c|c|c|c|c|}
\hline & Liver Injuries & Splenic rupture & Mesenteric injury with bleeding & Bowel injury with perforation or disruption & Multiple injuries & Total \\
\hline $\begin{array}{l}\text { Age } \\
60 \text { years and above }\end{array}$ & 9 & 2 & 6 & 12 & 4 & 33 \\
\hline$<60$ years & 21 & 19 & 7 & 23 & 19 & 89 \\
\hline
\end{tabular}

Table 4: Pattern of abdominal injuries in both groups. 


\section{ISS Score}

\begin{tabular}{|l|l|l|l|l|l|}
\hline & $\mathbf{1 - 8}$ & $\mathbf{9 - 1 5}$ & $\mathbf{1 6 - 2 5}$ & $\mathbf{> 2 5}$ & Total \\
\hline 60 Years and above & $26(17.44 \%)$ & $101(67.78 \%)$ & $20(13.42 \%)$ & $2(1.34 \%)$ & 149 \\
\hline$<60$ years Total & $9(5.96 \%)$ & $33(21.85 \%)$ & $92(60.92 \%)$ & $17(11.25 \%)$ & 151 \\
\hline
\end{tabular}

ISS= Injury severity score

Table 5: Comparison of ISS scores of two groups.

\begin{tabular}{|l|l|l|l|l|}
\hline Age group & No of patients & No of deaths & Percentage (\%) & ISS Score \\
\hline $10-20$ & 19 & 2 & 10.52 & $16-25$ \\
\hline $21-30$ & 22 & 1 & 4.54 & $>25$ \\
\hline $31-40$ & 46 & 2 & 4.34 & $>25$ \\
\hline $41-50$ & 31 & 0 & & \\
\hline $51-59$ & 33 & 2 & 6.06 & $16-25$ \\
\hline $60-70$ & 82 & 5 & 6.09 & $9-15$ \\
\hline $70-80$ & 59 & 11 & 18.64 & $9-15$ \\
\hline $81-90$ & 7 & 5 & 71.42 & $16-25$ \\
\hline$>90$ & 1 & 1 & 100 & $1-8$ \\
\hline
\end{tabular}

Table 6: Comparison of age group, number of deaths and ISS score.

Post-operative / invasive procedure complications of different severity and nature such as infections, chest complications and arrhythmias occurred in 39 (26.17\%) elderly patients compared to $17(11.25 \%)$ patients of younger age group $(\mathrm{P}<0.05)$. The average duration of hospital stay in group-A patients was $20.8 \pm 7.2$ days compared with $9.7 \pm 4.8$ days in group- $\mathrm{B}$ patients $(\mathrm{P}<0.001)$. The increased incidence of respiratory complications, associated diseases like diabetes Mellitis and renal disorders were found to be responsible for extended hospital stay in elderly patients.

\section{Mortality}

Of the total number, 22(14.76\%) patients of group -A died despite low ISS score compared to $7(4.63 \%)$ of group $-B$ patients $(p<0.001)$ as shown in Table 6. Of the total patients died in Group-A, seventeen (77\%) had one or the other co-morbidity while 2(29\%) of the 7 fatalities in Group-B had one or the other concurrent disease $(\mathrm{P}<0.001)$. The severe pain in rib fractures was found to decrease the respiratory volumes with development of basal atelectasis and infection. Comorbidities were seen in most of the fatalities in the elderly patients who died either within 24 hours of the incidence or post-operatively.

\section{Discussion}

Road traffic injuries are among the common causes of physical handicap, morbidity and mortality all over the world [8-10]. The actual incidence of such injuries is supposed to be much higher than reported in the literature $[11,12]$. A number of reports have cited an increase in the elderly trauma victims regardless of whether they are drivers themselves, pedestrians, or occupying the vehicles as passengers [13-17]. The current study compares the incidence, management and outcome of road traffic injuries in elderly patients (60 years and above) to those below 60 years of age. We found co-morbidities in a significant majority of elderly patients in our study compared to their younger counterparts (65.77\% V 13.4\%). This finding is consistent with a number of similar studies from different parts of the world [6,18$20]$. Although a number of studies $[17,21]$ found co-morbidities to be a major determinant of outcome of trauma in the elderly, Preston SD et al. [22], Mathilda HH [23] et al. and Milzmann DP et al. [24] did not find pre-existing diseases to be a determinant of outcome in elderly RTA victims. Occupants of vehicles, either private or public transport were common victims of group-A (74.49\%) while majority of group-B victims were drivers (62.9\%). A number of these younger drivers were claimed and found to be intoxicated and others were on their cell phones just before the collision. Similar factors are mentioned by other similar reports blaming careless and ruthless driving as a significant factor leading to fatal road traffic injuries [25]. The group -A patients received significantly high proportion of the chest injuries including haemothorax, pneumothorax, haemo-pneumothorax and rib fractures compared to group-B patients. This is consistent with results of other reports [19] and is attributed to increased vehicle occupancy by the elderly, using seat belts, osteoporosis, and decreased muscle mass etc $[26,27]$. In our study there is a high proportion of limb and hip bone fractures among group-A patients and majority of them were pedestrians compared to group- $B$ patients. This is consistent with the observation of Cheng $\mathrm{CH}$ et al. [28] claiming an increased incidence of injuries to extremities and significantly less abdominal injuries. This again coincides with our results. We, however, have a remarkably low incidence of splenic rupture in group-A patients compared to group-B patients. This is contrary to the results of other similar reports with high splenic rupture proportions in the elderly patients [1]. The vast majority of elderly victims in our study were vehicle occupants. There were few elderly drivers in our study who sustained injuries in road traffic accidents. This may be attributed to an unduly safe driving or because of a short distance driving by the elderly people in general and mostly in the day time. We observed a high mortality in the elderly group despite a comparable ISS score. This may be explained on the basis of a significantly high incidence of co-morbidities in the elderly victims in our study. A substantial body of literature also confirms this observation in elderly trauma patients [28-30]. The observations made in this study indicates a need to emphasize on aggressive and prompt management plan for elderly road traffic injury victims keeping in view their poor physiological reserves, associated co-morbidities and poor ability to tolerate trauma. Well-equipped trauma centers with trained trauma personnel need to be established in all major cities keeping in view the alarmingly increased incidence of fatal road traffic accidents in the developing world.

\section{Conclusion}

There are an increasing number of elderly patients fatally traumatized in road traffic accidents in our society. Keeping in view their less tolerability to trauma, the geriatric patients need a very special care with very prompt and aggressive treatment. A significant improvement can be achieved by establishing trauma centers with advance equipment and trained trauma care personnel especially in developing countries like Pakistan.

\section{References}

1. Patel VI, Thadepalli H, Patel PV, Mandal AK (2004) Thoracoabdominal injuries in the elderly: 25 years of experience. J Natl Med Assoc 96: 1553-1557.

2. Victorino GP, Chong TJ, Pal JD (2003) Trauma in the elderly patient. Arch Surg 138: 1093-1098.

3. Nagy KK, Smith RF, Roberts RR, Joseph KT, An GC, et al. (2000) Prognosis of penetrating trauma in elderly patients: a comparison with younger patients. J Trauma 49: 190-193.

4. Osler T, Hales K, Baack B, Bear K, Hsi K, et al. (1988) Trauma in the elderly Am J Surg 156: 537-543.

5. Schiller WR, Knox R, Chleborad W (1995) A five-year experience with severe injuries in elderly patients. Accid Anal Prev 27: 167-174.

6. Perdue PW, Watts DD, Kaufmann CR, Trask AL (1998) Differences in mortality between elderly and younger adult trauma patients: geriatric status increases risk of delayed death. J Trauma 45: 805-810.

7. Santora TA, Schinco MA, Trooskin SZ (1994) Management of trauma in the elderly patient. Surg Clin North Am 74: 163-186. 
Citation: Malik AM, Dal NA, Talpur KAH (2012) Road Traffic Injuries and their Outcome in the Elderly Patients (60 years and above). Does Age make a Difference? J Trauma Treat 1:129. doi:10.4172/2167-1222.1000129

8. Peden M, Hyder A (2002) Road traffic injuries are a global public health problem. BMJ 324: 1153.

9. Peden M (2005) Global collaboration on road traffic injury prevention. Int J Inj Contr Saf Promot 12: 85-91.

10. Perel P, McGuire M, Eapen K, Ferraro A (2004) Research on preventing road traffic injuries in developing countries is needed. BMJ 328: 895.

11. Bener A, Abu-Ziadan FM, Bensiali AK, Al-Mulla AA, Jaddan KS (2003) Strategy to improve road safety in developing countries. Saudi Med J 24: 603-608.

12. Hazen A, Ehiri JE (2006) Road traffic injuries: Hidden epidemics in less developed countries. J Natl Med Assoc 98: 73-82.

13. Kent R, Funk J, Crandall J (2003) How future trends in societal aging, air bag availability, seat belt use and fleet composition will affect serious injury risk and occurrence in the United States. Traffic inj prev 4: 24-32.

14. de Souza JA, Iglesias AC (2002) Trauma in the elderly. Rev Assoc Med Bras 48: 79-86.

15. McCoy GF, Johnston RA, Duthie RB (1989) Injury to the elderly in road traffic accidents. J Trauma 29: 494-497.

16. McMahon DJ, Schwab CW, Kauder D (1996) Co-morbidity and the elderly trauma patient. World J Surg 20: 1113-1119.

17. Perdue PW, Watts DD, Kaufmann CR, Trask AL (1998) Differences in mortality between elderly and younger adult trauma patients: geriatric status increases risk of delayed death. J Trauma 45: 805-810.

18. Victorino GP, Chong TJ, Pal JD (2003) Trauma in the elderly patient. Arch Surg 138: 1093-1098.

19. Lee WY, Cameron PA, Bailey MJ (2006) Road traffic injuries in the elderly. Emerg Med J 23: 42-46.
20. Johnson CL, Margulies DR, Kearney TJ, Hiatt JR, Shabot MM (1994) Trauma in the elderly: an analysis of outcomes based on age. Am Surg 60: 899-902.

21. Pickering SA, Esberger D, Moran CG (1999) The outcome following major trauma in the elderly. Predictors of survival. Injury 30: 703-706.

22. Smith DP, Enderson BL, Maull KI (1990) Trauma in the elderly: determinants of outcome. South Med J 83: 171-177.

23. Horst HM, Obeid FN, Sorensen VJ, Bivins BA (1986) Factors influencing survival of elderly trauma patients. Crit Care Med 14: 681-684.

24. Milzman DP, Boulanger BR, Rodriguez A, Soderstrom CA, Mitchell KA, (1992) Pre-existing disease in trauma patients: a predictor of fate independent of age and injury severity score. J Trauma 32: 236-243.

25. McCartt AT, Hellinga LA, Bratiman KA (2006) Cell phones and driving: review of research. Traffic Inj Prev 7: 89-106.

26. Martinez R, Sharieff G, Hooper J (1994) Three -point restraints as a risk factor for chest injury in the elderly. J Trauma 37: 980-984.

27. Bergeron E, Lavoie A, Clas D, Moore L, Ratte S, et al. (2003) Elderly trauma patients with rib fractures are at greater risk of death and pneumonia. J Trauma 54: 478-485.

28. http://www.hkcem.com/html/publications/Journal/2009-4/p224-232.pdf

29. Morris JA Jr, Mackenzie EJ, Damiano AM, Bass SM (1990) Mortality in trauma patients: the interaction between host factors and severity. J Trauma 30: 14761482.

30. http://www.sciencedirect.com/science/article/pii/S0953711297800403 